JURNAL TERKNOSAINS

VOLUME 1

No. 2, 22 Juni 2012

Halaman 71-143

\title{
PENGARUH TEKANAN PISTON PADA PENGATURAN KATUP SOLENOID PROPORSIONAL DUA ARAH TERHADAP LAJU ALIRAN AIR PADA SISTEM KALIBRASI PISTON PROVER OT-400
}

\author{
Jalu Ahmad Prakosa dan Bernadus H. Sirenden \\ Pusat Penelitian Kalibrasi, Instrumentasi dan Metrologi (KIM) LIPI \\ Kompleks Puspiptek Serpong, Tangerang, Banten 15314 \\ Email: jalu@kim.lipi.go.id dan ben@kim.lipi.go.id
}

\begin{abstract}
In order to use piston prover OT-400 calibrator more effective is to know the relationship between pressure piston and water flow rate. Water flow rate measurement by using piston pressure variation and setting of proportional directional solenoid valve has been done on piston prover OT-400 calibration sytems. Selection variation of piston pressure condition has been done at four measuring points there are 20 PSI, 42.5 PSI, 62.5 PSI and 80 PSI. Giving of voltage variation for ascending and declining to the solenoid is to set the opening and closing its valve. From the measurement results obtained that the water flow rate is proportional to the piston pressure used. Graph of water flow rate $(Q)$ with unit of liters / minute versus the piston pressure $(P)$ with unit of PSI within the setting of proportional directional solenoid valve on the piston prover OT-400 calibrator has linear type that is $Q=0.002$. $P$ +0.151 with $R^{2}=0,998$. While the graph of the average uncertainty value of the measuring point versus pressure piston is not a linear form with the smallest value of $2.31 \%$ on the use of piston pressure of 80 PSI
\end{abstract}

Keywords: Piston pressure, water flow rate, voltage setting, solenoid valve, piston prover OT-400.

\begin{abstract}
ABSTRAK
Agar penggunaan kalibrator piston prover OT-400 lebih efektif perlu diketahui hubungan tekanan piston yang digunakan dengan laju aliran air. Telah dilakukan pengukuran nilai laju aliran air dengan variasi tekanan piston dan pengaturan katup solenoid proporsional dua arah pada sistem kalibrasi piston prover OT-400. Pemilihan variasi kondisi tekanan piston dilakukan pada empat titik ukur yaitu 20 PSI, 42,5 PSI, 62,5 PSI dan 80 PSI. Pemberian variasi tegangan menaik dan menurun pada solenoid dilakukan untuk mengatur buka tutup katupnya. Dari hasil pengukuran didapat bahwa laju aliran air sebanding dengan tekanan piston yang digunakan. Grafik laju aliran air $(\mathrm{Q})$ dengan satuan liter / menit versus tekanan piston $(\mathrm{P})$ dengan satuan PSI dalam pengaturan katup solenoid proporsional dua arah pada kalibrator piston prover OT-400 berbentuk linear yaitu $Q=0,002 . P+0,151$ dengan $R^{2}=0,998$. Sedangkan grafik nilai ketidakpastian rata-rata terhadap titik ukurnya versus tekanan piston tidak berbentuk linear dengan nilai terkecil yaitu 2,31 \% pada penggunaan tekanan piston 80 PSI.
\end{abstract}

Kata Kunci: Tekanan piston, laju aliran air, pengaturan tegangan, katup solenoid, piston prover OT400. 


\section{PENGANTAR}

Untuk menjamin akurasi dan ketepatan pengukuran laju aliran air, maka alat ukur laju aliran air atau water flowmeter perlu dikalibrasi dengan suatu standar yang tertelusur sampai standar primer dengan memperoleh pengakuan internasional. Standar primer merupakan standar tertinggi yang diturunkan langsung dari definisi suatu besaran dan secara formal hanya boleh dikembangkan oleh satu NMI dalam suatu negara. Piston prover merupakan salah satu jenis standar primer untuk besaran laju aliran fluida. Kalibrator piston prover OT-400 berfungsi untuk mengkalibrasi alat ukur laju aliran air dalam rentang ukur 4 liter/menit sampai 1300 liter/menit dengan ketidakpastian 0,12\% yang telah melalui proses akreditasi peer review oleh Komite Akreditasi Nasional pada tanggal 7 - 8 November 2011.

Piston prover bekerja berdasarkan prinsip positive displacement. Sejumlah volume cairan yang terletak di dalam silinder akan dipindahkanoleh sebuah piston dengan tekanan piston yang digunakan untuk mendorong air pada kalibrator piston prover OT-400. Semakin besar tekanan piston, maka semakin besar pula gaya dorong piston dalam menggerakan aliran air. Udara kering bertekanan digunakan untuk menghasilkan tekanan pada piston tersebut. Kompresor dan mesin pengering digunakan untuk menghasilkan udara kering bertekanan tersebut.

Perlu dipelajari pengaruh tekanan piston terhadap laju aliran air, sehingga penggunaan tekanan piston dapat disesuaikan dengan kebutuhan dan tujuan penggunaan piston prover OT-400. Adapun pengaturan buka tutup katup solenoid proporsional dua arah telah dilakukan guna keperluan proses penentuan K-Faktor sistem kalibrasi piston prover OT-400 secara otomatis pada penelitian sebelumnya (Jalu \& Bernadus, 2011). Selain untuk keperluan penelitian, pengaruh tekanan piston terhadap pengukuran laju aliran air dapat digunakan untuk menghemat energi dalam pengoperasian kalibrator piston prover OT-400 sehingga himbauan program hemat energi dari pemerintah pun nantinya dapat dilaksanakan dengan baik (Susilo, 2008). Tujuan penelitian ini adalah mempelajari pengaruh tekanan piston terhadap pengukuran laju aliran air pada sistem kalibrasi piston prover OT-400.

\section{Kerangka Pemikiran \\ Tekanan Piston Pada Sistem Kalibrasi Piston Prover OT-400}

Pada kalibrattor piston prover OT-400, udara kering bertekanan mendorong piston secara presisi dan terasah pada tabung aliran dengan laju yang konstan, memindahkan cairan dalam tabung dan menyebabkannya mengalir melalui bagian yang dites, yang berisi meteran yang terkalibrasi kemudian cairan yang dipindahkan disimpan dalam reservoir cairan. Tekanan operasional yang diberikan pada piston saat melakukan kalibrasi adalah 80 PSI.

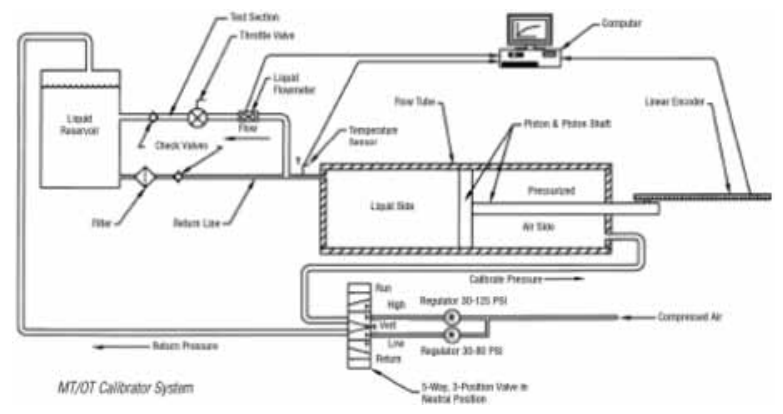

Gambar 1.

Skema kerja piston prover OT-400

\section{Pengaturan Katup Solenoid Proporsional Dua Arah}

Sebuah katup solenoid adalah katup elektromekanis digunakan untuk mengatur fluida mengalir berupa cairan atau gas. Sebuah katup solenoid memiliki dua bagian utama yaitu solenoid dan katup. Solenoid mengonversi energi listrik menjadi energi mekanik untuk membuka atau menutup katup secara mekanik. Sebuah pegas dapat digunakan untuk menahan katup untuk membuka atau menutup sementara katup 
tidak diaktifkan. Berikut ini Gambar 2 diagram desain dasar katup solenoid yang menjelaskan prinsip dasar katup solenoid :
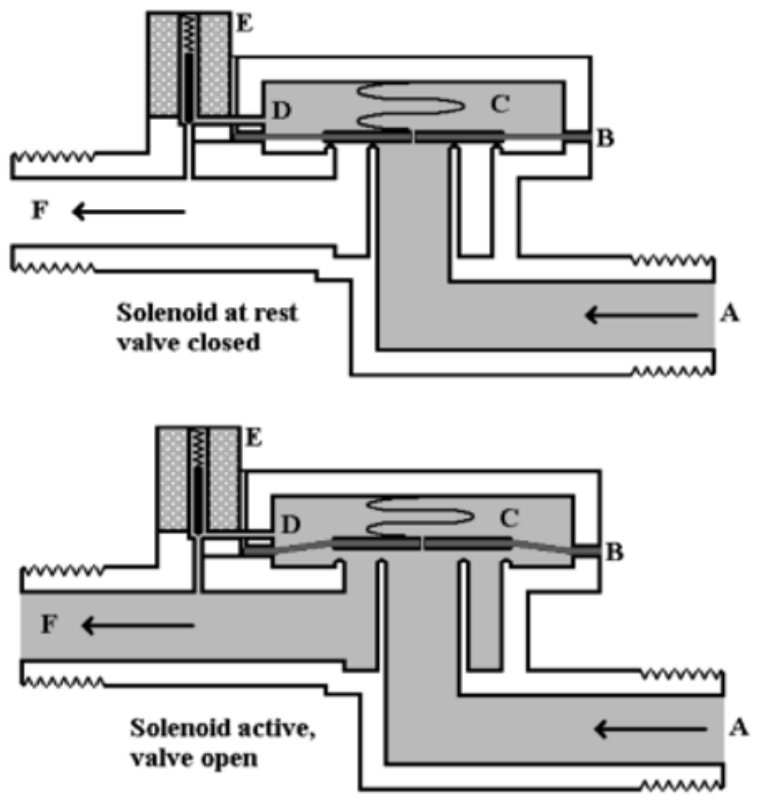
A. Input side
B. Diaphragm
C. Pressure chamber
D. Pressure relief conduit
E. Solenoid
F. Output side

Gambar 2.

Diagram desain dasar katup solenoid

Telah digunakan katup solenoid proporsional dua arah tipe Proportional Solenoid Vale (PSV) dengan nomor seri 2631504 produksi Aalborg dalam penelitian ini. PSV katup proportional elektromagnetik dirancang untuk menanggapi masukan daya (tegangan/ arus) dengan variabel yang proporsional untuk mengatur laju aliran cairan dan gas. Untuk menambahkan keamanan PSV katup dibuat normally closed (NC) ketika de-energized berfungsi sebagai saklar "on-off" katup. Laju aliran dikendalikan dengan meningkatkan atau menurunkan tegangan yang diberikan pada koil. Hal ini menyebabkan gaya magnetik yang mengangkat inti katup sehingga

memungkinkan fluida mengalir. Katup ini terbuat dari stainless steel yang tersedia di lima jenis ukuran yang meliputi aliran berkisar dari 3,5 L / menit - $100 \mathrm{~L} /$ menit untuk gas dan 125 ml / menit - 2,85 L / menit untuk air. Berikut ini ditampilan katup solenoid proporsional dua arah tipe Proportional Solenoid Vale (PSV) produksi Aalborg pada Gambar 3 berikut ini.

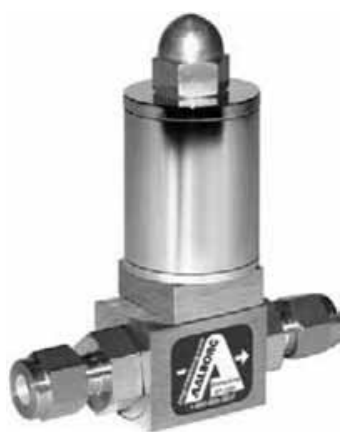

Gambar 3.

Katup solenoid proporsional dua arah PSV Aalborg

\section{Pengukuran Laju Aliran Air pada Kalibrator Piston Prover OT-400}

Microtrack/Omnitrack OT-400 adalah sebuah sistem yang berfungsi mengkalibrasi alat ukur laju aliran air atau flowmeter (flowmeter calibrator). Sistem ini bekerja berdasarkan prinsip positive displacement, yaitu sejumlah volume cairan yang terletak di dalam silinder akan dipindahkan oleh sebuah piston. Piston digerakkan dengan menggunakan udara bertekanan dari kompresor. Perpindahan piston tersebut berkorelasi dengan volume yang telah berpindah. Oleh karena itu, sistem ini juga dinamakan piston prover (Bernadus, 2009).

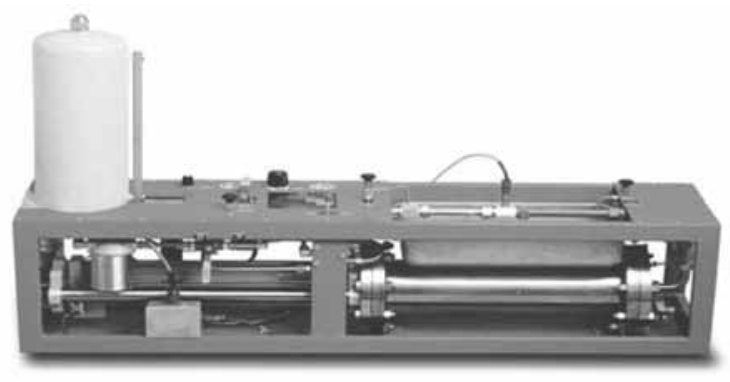

Gambar 4.

Piston Prover OT-400 
Pengukuran perpindahan piston di dalam silinder dilakukan dengan cara tangkai piston diletakkan sebuah linear encoder/translator yang berfungsi mengukur posisi dan/atau kecepatan perpindahan piston. Sinyal pulsa linear encoder tersebut dikirim oleh sebuah perangkat elektronik ke sebuah kartu data akusisi yang berada di dalam komputer. Sedangkan laju aliran didefinisikan sebagai perbandingan antara volume dengan waktu dalam persamaan (1) di bawah ini.

(1) $Q=\frac{\Delta V}{\Delta t}$

yaitu :

\begin{tabular}{|l|l|l|}
\hline $\mathrm{Q}$ & $=$ & laju aliran, liter/menit \\
\hline$\Delta \mathrm{V}$ & $=$ & perubahan volume, liter \\
\hline$\Delta \mathrm{t}$ & $=$ & perubahan waktu, menit \\
\hline
\end{tabular}

Translator $\mathrm{K}$ atau K-Faktor adalah sebuah konstanata yang menghubungkan pulsa yang dihasilkan oleh translator/encoder dengan volume cairan yang berpindah. Penentuan Konstanta K-Faktor dilakukan dengan proses water draw untuk sejumlah pulsa tertentu yang dibaca dari encoder. Sedemikian hingga didapatkan sebuah konstanta yang menghubungkan antara pulsa yang dikeluarkan oleh encoder dengan volume cairan yang dipindahkan oleh piston. K-Faktor berpadanan dengan volume, sehingga untuk mendapatkan nilai laju aliran, digunakan frekuensi encoder sesuai persamaan di bawah ini.

(2) $Q=\frac{f .60}{\text { K- Faktor }}$ yaitu:

\begin{tabular}{|l|l|l|}
\hline $\mathrm{f}$ & $=$ & $\begin{array}{l}\text { frekuensi encoder, pulsa / sekon } \\
\text { atau Hz }\end{array}$ \\
\hline K-Faktor & $=$ konstanta K-Faktor, pulsa / liter \\
\hline
\end{tabular}

Berdasarkan sertifikat calibrator yang dikeluarkan oleh pabrik pembuat Flow
Technology Inc., maka nilai K-Faktor adalah 2631,20 pulsa per- liter.

\section{Metode Pengukuran}

Tempat pengukuran dilakukan di laboratorium aliran air sub- bidang gaya dan massa, Pusat Penelitian Kalibrasi, Instrumentasi, dan Metrologi (KIM) LIPI pada tanggal 7 April 2011 pada pukul 09.0016.00 WIB. Pengaruh tekanan piston terhadap pengukuran laju aliran air dipelajari dengan cara dilakukan pengukuran pada empat variasi titik ukur kondisi tekanan piston yaitu, 20 PSI, 42,5 PSI, 62,5 PSI dan 80 PSI karena kemudahan dalam mengkondisikan tekanan piston pada titik ukur tersebut. Pengaturan buka tutup katup solenoid proporsional dua arah dilakukan dengan memberikan variasi tegangan menaik dan menurun. Digunakan pengaturan tegangan daripada arus listrik karena dari hasil uji pengukuran laju aliran air diketahui bahwa nilainya lebih stabil dan linear. Pengukuran laju aliran air sesuai rumus persamaan (2) di atas bahwa nilai frekuensi pulsa didapat dari encoder dan timer pada kalibrator piston prover OT-400.

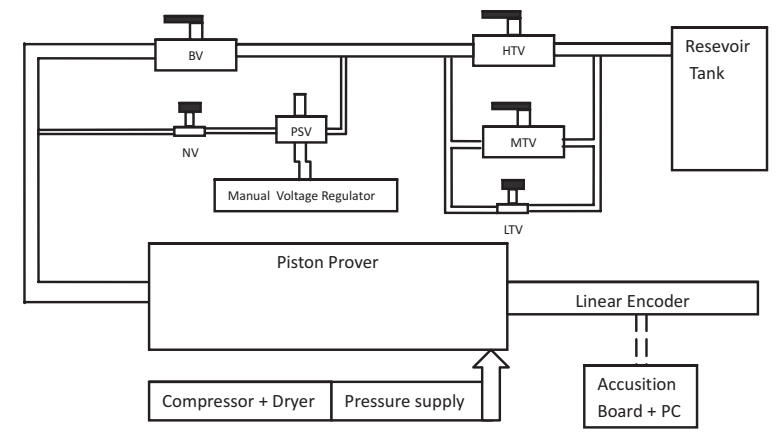

\begin{tabular}{|l|l|l|}
\hline BV & $:$ & Ball Valve \\
\hline NV & $:$ & Needle Valve \\
\hline PSV & $:$ & Proportional Solenoid Valve \\
\hline HCV & $:$ & High Throttling Valve \\
\hline MCV & $:$ & Medium Throttling Valve \\
\hline LCV & $:$ & Low Throttling Valve \\
\hline
\end{tabular}

Gambar 5.

Diagram sistem pengukuran 
Selama percobaan BV dan HTV akan ditutup penuh, sementara NV, MTV dan LTV akan dibuka penuh. Tegangan listrik pada regulator akan dinaikkan dari 7-17 volt kemudian diturunkan dari 17 - 3 volt agar laju aliran air dapat diukur dengan jarak tiap titik ukur / span acak dengan pengukuran diulang sebanyak tiga kali. Setiap pengulangan pengukuran diberi jeda waktu 15 menit sebelum melakukan pengukuran selanjutnya agar lebih dapat dipastikan katup solenoid tertutup penuh dan bersih dari sisa medan magnet di dalamnya. Nilai rata-rata data dihitung dengan perumusan di bawah ini:

(3) $\bar{x}=\frac{\sum x_{i}}{n}$

Yaitu:

$\bar{x}=$ Nilai rata-rata data pengukuran

$x_{i}=$ Nilai data suatu pengukuran

$\mathrm{n}=$ Jumlah data dalam pengukuran

Evaluasi ketidakpastian pengukuran data tipe A dihitung dengan perumusan merujuk standar perhitungan ISO/TAG 4: 1993 - Guide to the Expression of Uncertainty in Measurement berikut ini ${ }^{[9]}$ :

(4)

$$
\mathrm{u}_{\mathrm{i}}=\frac{s}{\sqrt{n}}=\frac{\sqrt{\frac{\sum\left(x_{i}-\bar{x}\right)^{2}}{n-1}}}{\sqrt{n}}
$$

(5) $\quad v_{i}=n-1$

$$
\mathrm{u}_{\mathrm{c}}=\sqrt{\sum c_{i}{ }^{2} \cdot u_{i}{ }^{2}}
$$

$$
\mathrm{v}_{\mathrm{eff}}=\frac{u_{c}{ }^{4}}{\sum \frac{c_{i}{ }^{4} \cdot u_{i}{ }^{4}}{v_{i}}}
$$

$$
\mathrm{U}=\mathrm{k} \cdot \mathrm{u}_{\mathrm{i}}
$$

Yaitu:

$\mathrm{u}_{\mathrm{i}}=$ Ketidakpastian data ke-i pengukuran

$u_{c}=$ Ketidakpastian gabungan pengukuran

$\mathrm{s}=$ Nilai simpangan baku atau standar deviasi

$x_{i}=$ Nilai data ke-i

$c_{i}=$ Koefisien sensitivitas data ke-i

$\mathrm{v}_{\mathrm{i}}=$ Derajat kebebasan data ke-i pengukuran

$\mathrm{v}_{\text {eff }}=$ Derajat kebebasan efektif pengukuran

$\mathrm{k}=$ Faktor cakupan sesuai faktor-t student

$\mathrm{U}=$ Ketidakpastian terentang

\section{PEMBAHASAN}

Hasil pengukuran laju aliran air (Q) terhadap pemberian tegangan $(\mathrm{V})$ menaik dari 7 - 17 volt untuk membuka katup solenoid ditampilkan dengan variasi kondisi tekanan piston yaitu 20 PSI, 42,5 PSI, 62,5 PSI dan 80 PSI pada Gambar 6 di bawah ini :

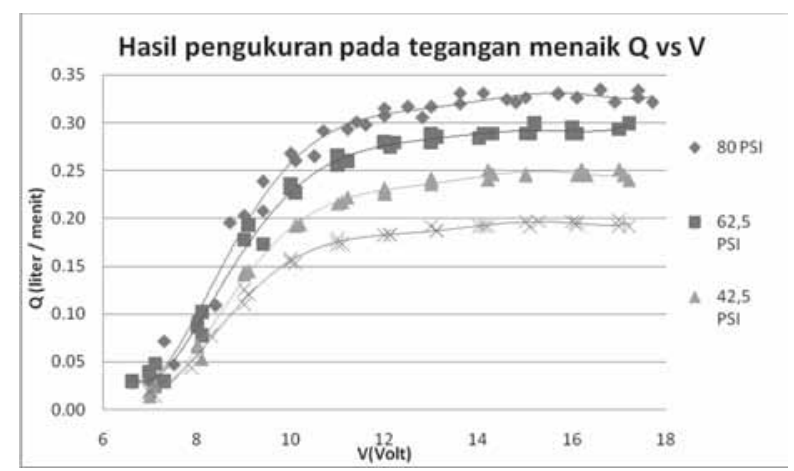

Gambar 6.

Grafik hasil pengukuran data laju aliran air terhadap pemberian tegangan menaik untuk membuka katup pada variasi tekanan piston yang diberikan

Hasil pengukuran laju aliran air (Q) terhadap pemberian tegangan $(\mathrm{V})$ menurun dari 17 - 3 volt untuk menutup katup solenoid ditampilkan dengan variasi kondisi tekanan piston yaitu 20 PSI, 42,5 PSI, 62,5 PSI dan 80 PSI pada Gambar 7 di bawah ini. 


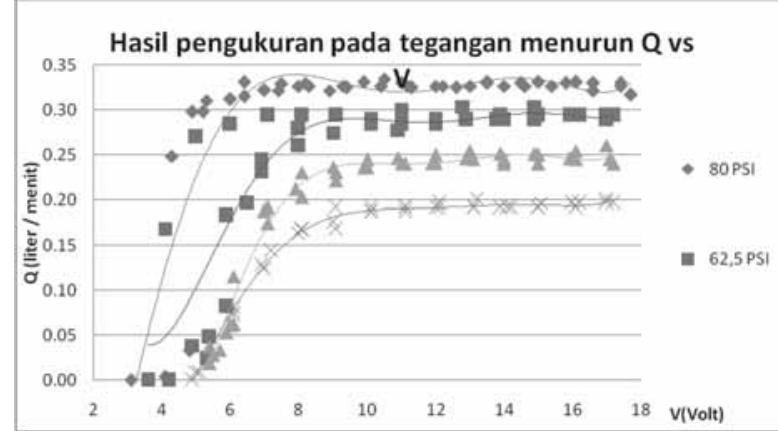

Gambar 7.

Grafik hasil pengukuran data laju aliran air terhadap pemberian tegangan menurun untuk menutup katup pada variasi tekanan piston yang diberikan

Terlihat pada grafik Gambar 6 dan Gambar 7, nilai laju aliran air lebih stabil dan maksimal ketika katup solenoid terbuka penuh pada rentang pemberian tegangan 1417 volt, sehingga perlu dianalisa nilai ratarata laju aliran air beserta ketidakpastiannya sesuai perumusan (3) sampai (8) di atas pada tiap titik ukur tekanan piston tersebut yang ditampilkan pada Tabel 1 berikut ini :

\section{Tabel 1.}

Hasil pengukuran nilai rata-rata laju aliran air pada tiap variasi titik ukur tekanan piston yang diberikan.

\begin{tabular}{|l|l|l|l|l|l|}
\hline & \multicolumn{2}{|}{$\begin{array}{r}\text { Pemberian tegangan } \\
\text { menaik }\end{array}$} & \multicolumn{2}{|r|}{$\begin{array}{r}\text { Pemberian tegangan } \\
\text { menurun }\end{array}$} & $\%$ \\
$\begin{array}{c}\text { Tekanan } \\
\text { piston } \\
\text { (PSI) }\end{array}$ & $\begin{array}{r}\text { Laju aliran air } \\
\text { (liter / menit) }\end{array}$ & $(U / Q) \%$ & $\begin{array}{c}\text { Laju aliran air } \\
\text { (liter / menit) }\end{array}$ & $(U / Q) \%$ & $\begin{array}{c}\text { naik- } \\
\text { turun }\end{array}$ \\
\hline 80 & $0,3300 \pm 0,0082$ & 2,52 & $0,3271 \pm 0,0069$ & 2,10 & 2,31 \\
\hline 62,5 & $0,2914 \pm 0,0099$ & 3,41 & $0,2931 \pm 0,0091$ & 3,11 & 3,26 \\
\hline 42,5 & $0,2458 \pm 0,0063$ & 2,57 & $0,2473 \pm 0,0093$ & 3,78 & 3,18 \\
\hline 20 & $0,1940 \pm 0,0054$ & 2,81 & $0,1948 \pm 0,0063$ & 3,22 & 3,01 \\
\hline
\end{tabular}

Dari data-data Tabel 1 di atas dapat dibuat grafik laju aliran air $(\mathrm{Q})$ versus tekanan piston $(\mathrm{P})$ yang ditampilkan pada Gambar 7 dan ketidakpastian rata-rata terhadap titik ukurnya $(U / Q)$ versus tekanan piston $(P)$ yang ditampilkan pada Gambar 8 berikut ini :

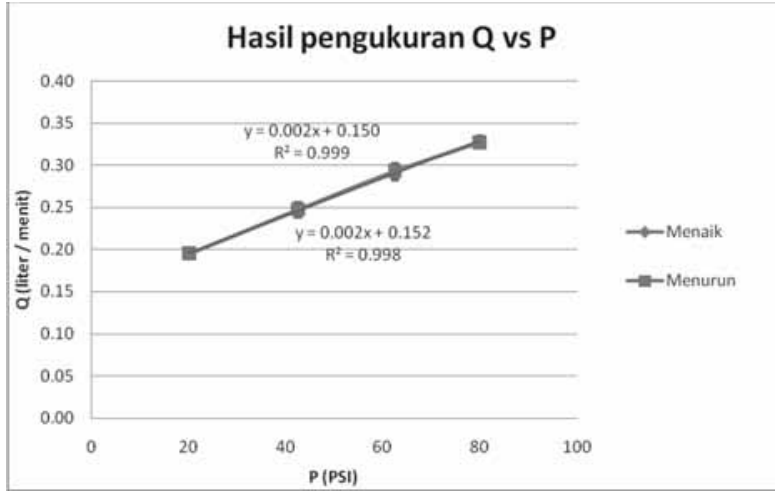

Gambar 8.

Grafik hasil pengukuran data nilai rata-rata laju aliran air terhadap variasi tekanan piston yang diberikan

Terlihat pada Gambar 8, grafik nilai rata-rata laju aliran air versus tekanan piston pada pemberian tegangan menaik dengan menurun hampir identik. Gradien grafik keduanya sama yaitu 0,002 dimana konstanta hanya berbeda sedikit. Jika masing-masing konstantanya dirata-rata maka didapat rumus persamaan relasi laju aliran air (Q) dengan tekanan piston $(\mathrm{P})$ adalah

$$
\text { (9) } \mathrm{Q}=0,002 \cdot \mathrm{P}+0,151 \text { dengan } \mathrm{R}^{2}=0,998
$$

Dari perumusan persamaan (9) dapat diprediksi laju aliran air yang dapat dihasilkan sistem kalibrasi piston prover OT-400 berdasarkan tekanan piston yang digunakan. Nilai $R$-squared $\left(R^{2}\right)=0,998$, yang mendekati 1 mengartikan bahwa persamaan grafik tersebut makin baik mendekati kebenaran model regresi untuk keseragaman setiap titik ukurnya. Sesuai jenis grafik laju aliran air versus tekanan piston yang linear dapat disimpulkan bahwa laju aliran air sebanding atau berbanding langsung dengan tekanan piston yang diberikan. Secara teori hipotesa, gradien laju aliran air terhadap tekanan piston pada kalibrator piston prover OT-400 yaitu 0,02 akan selalu tetap dan berlaku universal terhadap pemakaian flowmeter atau alat kendali laju aliran air lainnya selain katup solenoid proporsional dua arah ini dimana nantinya 
yang berbeda hanya konstanta penjumlahannya saja sesuai jenis flowmeter atau alat kendali laju aliran air yang akan digunakan.

Salah satu fungsi mengetahui pengaruh tekanan piston terhadap pengukuran laju aliran air yaitu untuk menghemat energi dalam pengoperasian kalibrator piston prover OT-400 selain untuk keperluan penelitian lainnya. Semakin besar tekanan piston digunakan, maka semakin besar daya listrik atau energi yang diperlukan kompresor dan mesin pengering untuk menghasilkan udara kering bertekanan guna menyediakan tekanan pada piston tersebut. Pada sistem kalibrasi piston prover OT-400 dapat digunakan tekanan piston dari 0 - 160 PSI, tetapi berdasarkan perumusan persamaan 9 di atas jika hanya ingin menghasilkan laju aliran air sebesar 0,3 liter/menit dengan pengaturan solenoid proporsional dua arah pada kalibrator piston prover OT-400, tidak perlu menggunakan tekanan piston lebih dari 63 PSI. Dengan demikian penggunaan daya listrik pada kompresor penyuplai udara bertekanan untuk menggerakan piston dapat dihemat dan disesuaikan dengan rentang nilai laju aliran yang ingin digunakan. Dengan demikian dapat dilakukan penghematan energi dengan menggunakan tekanan piston sesuai kebutuhan rentang nilai laju aliran air yang dibutuhkan ketika memberi pelayanan jasa kalibrasi flowmeter kepada masyarakat industri sesuai dengan program hemat energi yang digencarkan pemerintah terutama pada lembaga pemerintah.

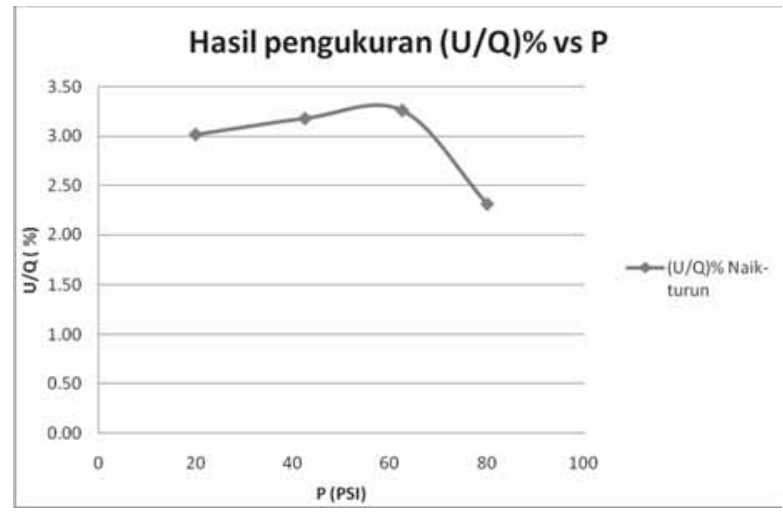

Gambar 9.

Grafik hasil pengukuran ketidakpastian rata-rata terhadap titik ukurnya versus variasi tekanan piston yang diberikan
Nampak pada Gambar 9, grafik nilai ketidakpastian rata-rata terhadap titik ukurnya $(U / Q)$ versus tekanan piston tidak berbentuk linear. Nilai ketidakpastian ratarata terhadap titik ukurnya terkecil yaitu 2,31 $\%$ terdapat pada pemberian tekanan piston 80 PSI sehingga penggunaan tekanan piston sebesar 80 PSI baik untuk dijadikan standar pengoperasian standar acuan laju aliran air piston prover OT-400 dalam mengkalibrasi dan menurunkan nilai/diseminasi alat ukur laju aliran air / flowmeter. Sedangkan nilai ketidakpastianrata-rataterhadaptitikukurnya terkecil kedua yaitu 3,01 \% dalam rentang ukur paling rendah $0,1944 \pm 0,0083$ liter/menit terdapat pada pemberian tekanan piston 20 PSI cukup baik untuk digunakan dalam penentuan K-Faktor sistem kalibrasi piston prover OT-400 menggunakan katup solenoid yang dikendalikan komputer pada penelitian sebelumnya. ${ }^{[6]}$ Oleh karena itu, penggunaan tekanan piston dapat disesuaikan dengan kebutuhan dan tujuan penggunaan piston prover OT-400 seperti untuk mengkalibrasi flowmeter atau penentuan K-Faktor atau tujuan ilmiah lainnya.

\section{SIMPULAN}

Laju aliran air sebanding dengan tekanan piston yang digunakan pada sistem kalibrasi piston prover OT-400. Grafik laju aliran air (Q) dengan satuan liter / menit versus tekanan piston $(\mathrm{P})$ dengan satuan PSI dalam pengaturan katup solenoid proporsional dua arah pada kalibrator piston prover OT400 berbentuk linear yaitu $\mathrm{Q}=0,002 . \mathrm{P}+$ 0,151 dengan $R^{2}=0,998$. Sedangkan grafik nilai ketidakpastian rata-rata terhadap titik ukurnya $(\overline{U / Q})$ versus tekanan piston tidak berbentuk linear dengan nilai terkecil yaitu $2,31 \%$ pada penggunaan tekanan piston 80 PSI.

Pada persamaan $\mathrm{Q}=0$,002.P $+\mathrm{c}$, perlu diuji lagi gradien laju aliran air dalam satuan liter / menit terhadap tekanan piston dengan satuan PSI pada kalibrator piston prover OT400 yaitu sebesar 0,02 dengan memperbanyak 
sampel pengujian terhadap jenis flowmeter dan alat kendali laju aliran air selain katup solenoid proporsional dua arah, guna lebih memastikan nilai gradien tersebut dan nilai karakteristik nilai konstanta c untuk masingmasing jenis flowmeter dan alat kendali laju aliran air. Perlu dibuat standar dan prosedur kerja penggunaan tekanan piston yang disesuaikan dengan kebutuhan dan tujuan penggunaan piston prover OT-400 piston prover OT-400 yaitu dengan contoh sebagai berikut :

1. Penggunaan tekanan piston disesuaikan dengan rentang nilai laju aliran air yang dibutuhkan sesuai persamaan $\mathrm{Q}=0,002 \cdot \mathrm{P}+0,151$ sehingga energi pengoperasian piston prover OT-400 dapat dihemat.

2. Penggunaan tekanan piston sebesar 80 PSI baik untuk dijadikan standar pengoperasian standar acuan laju aliran air piston prover OT-400 dalam mengkalibrasi dan mendiseminasi alat ukur laju aliran air / flowmeter karena memiliki nilai ketidakpastian rata-rata terhadap titik ukurnya terkecil dan rentang ukur yang besar.

3. Penggunaan tekanan piston sebesar 20 PSI baik untuk dijadikan standar pengoperasian standar acuan laju aliran air piston prover OT-400 dalam penentuan K-Faktor sistem kalibrasi piston prover OT-400 menggunakan katup solenoid karena memiliki nilai ketidakpastian rata-rata terhadap titik ukurnya terkecil kedua dan rentang ukur yang kecil guna penentuan K-Faktor dengan water draw.

4. Penggunaan tekanan piston disesuaikan dengan kebutuhan dan tujuan penggunaan piston prover OT-400 lainnya.

Penulis mengucapkan terima kasih kepada manajemen KIM-LIPI dan Islamic Development Bank (IDB) sebagai penyandang dana fasilitas kalibrator piston prover OT400 serta manajemen dan tim teknis DIPA Tematik KIM-LIPI 2009 yang telah membantu secara administratif maupun teknis sehingga katup solenoid proporsional dua arah PSV Aalborg ini dapat tersedia di laboratorium metrologi aliran ini.

\section{DAFTAR PUSTAKA}

Aalborg, 2011, Aalborg PSV Proportionating Electromagnetic Valve. (http://www. aalborg.com/images/file_to_download/ en_Aalborg_EM201101_PSV_\&_PSVD. pdf, diakses 15 April 2011).

Komite Akreditasi Nasional, 2011, Assesment Report of Puslit KIM-LIPI: assessed fields of volume flowrate 7 - 9 November 2011, Tangerang.

Flow Technology Incorporated, 2003, Microtrak and Omnitrak ${ }^{\mathrm{TM}}$ Primary Standard Liquid Calibration Systems, Arizona: FTI.

Flow Technology Incorporated, 2005, Microtrack/Omnitrack OT-400 Calibrator Installation, Operation and Manitenance Manual TM-86611 REV.J. Arizona: FTI.

Flow Technology Incorporated, 2005, Calware Variable Definition (Rev A), Arizona: FTI.

Flow Technology Incorporatedm, 2007, OT400 Calibrator Certificate, Arizona: FTI.

International Organisation for Standardisation(ISO), 1993, ISO/TAG 4: 1993 - Guide to the Expression of Uncertainty in Measurement, Paris : BIPM, ISO, IEC, dan OIML.

Prakosa, Jalu A. dan Sirenden, Bernadus H, 2011, Analisa Pengaruh Pengaturan Buka Tutup Katup Solenoid Proporsional Dua Arah Terhadap Laju Aliran Air Pada Sistem Kalibrasi Piston Prover OT-400, Pertemuan dan Presentasi Ilmiah(PPI) KIM ke-37, Tangerang: Pusat Penelitian Kalibrasi, Instrumentasi dan Metrologi (KIM) LIPI, ISSN 0852 - 002 X. 
JALU AHMAD PRAKOSA DAN BERNADUS H. SIRENDEN PENGARUH TEKANAN PISTON PADA PENGATURAN KATUP SOLENOID PROPORSIONAL DUA ARAH TERHADAP LAJU ALIRAN ...

Sirenden, Bernadus H, 2009, Perbandingan Pengukuran Laju Aliran Antara Metode Volume Dasar dengan TranslatorK di Inteval Gerbang 100-500 ms pada OT400 Liquid Flow Calibrator, Pertemuan dan Presentasi Ilmiah(PPI) KIM ke-35, Tangerang: Pusat Penelitian Kalibrasi, Instrumentasi, dan Metrologi (KIM) LIPI.
Wikipedia Foundation, 2011, Solenoid valve, (http://en.wikipedia.org/wiki/ Solenoid_valve, diakses 15 April 2011).

Republik Indonesia, 2008, Instruksi Presiden Nomor 2 Tahun 2008 Tentang Penghematan Energi dan Air, Jakarta. 